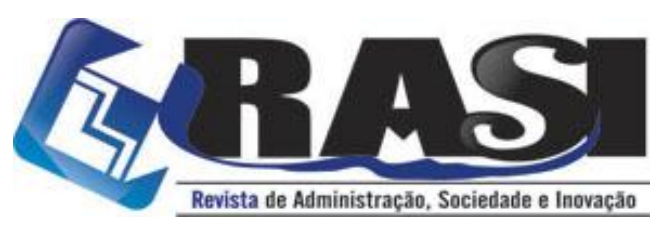

http://www.rasi.uff.br

RASI, Volta Redonda/RJ, v. 3, n. 2, pp. 152-174, jul./dez. 2017

\title{
Avaliação de aspectos e atributos de sustentabilidade para priorização de projetos de dragagem em portos
}

\author{
Ilton Curty Leal Junior (UFF) - iltoncurty@id.uff.br \\ Vanessa de Almeida Guimarães (UFRJ) - vanessaguim@hotmail.com \\ Newton Narciso Pereira (UFF) - newtonnaval@gmail.com
}

\begin{abstract}
RESUMO:
Dada a relevância dos portos para a economia de um país e para a competitividade das empresas, neste artigo apresentam-se aspectos e atributos, identificados por meio da literatura nacional e internacional, utilizados para priorizar a dragagem em portos marítimos. Com base em pesquisa realizada com os stakeholders, foi definida a importância de cada aspecto e atributo no processo de tomada de decisão considerando-se três grupos de respondentes: academia, empresa e governo. Assim, por meio da aplicação da Analytic Hierarchy Process AHP, identificou-se que há consenso entre os grupos pesquisados quanto a maior importância dos atributos relacionados ao aspecto econômico enquanto que os sociais são considerados menos importantes. Com base nos resultados, conclui-se que é necessário combinar diferentes atributos para priorização dos projetos de dragagem nos portos brasileiros e que há diferentes visões entre os stakeholders. Como implicação prática, este artigo fornece informações para suportar as políticas públicas do setor de transporte e a tomada de decisão pelos gestores de organizações públicas e privadas. Além disso, aponta uma direção para as pesquisas de acadêmicos com relação ao tema. Para novos estudos propõe-se considerar um maior número de stakeholders e utilizar os aspectos e atributos considerados relevantes para priorizar portos a serem dragados em um caso real.
\end{abstract}

PALAVRAS-CHAVE: dragagem, portos marítimos, priorização de projetos, stakeholders, atributos

\section{Assessment of aspects and attributes of sustainability for prioritization of dredging projects in ports}

\begin{abstract}
:
Given the relevance of ports to the economy of a country and the competitiveness of companies, in this paper we present aspects and attributes, identified in the national and international literature, used to prioritize dredging in seaports. Based on research carried out with the stakeholders, the importance of each aspect and attribute in the decision making process was defined considering three groups of respondents (academia, company and government). Thus, through the application of the Analytic Hierarchy Process - AHP, we identified that there is consensus among the stakeholders regarding the greater importance of the attributes related to the economic aspect while the social ones are considered less important. Based on the results, we concluded that it is necessary to combine different attributes for prioritization of the dredging projects in the Brazilian ports and that there are different visions among the stakeholders. As a practical implication, this paper provides information to support the public policies of the transportation sector and decision making by managers of public and private organizations. It also points the way to academic research on the subject. For new studies, it is proposed to consider a greater number of stakeholders and to use the aspects and attributes considered relevant to prioritize ports to be dredged in a real case.
\end{abstract}

KEYWORDS: dredging, maritime ports, prioritization of projects, stakeholders, attributes

\begin{tabular}{c} 
R. Desembargador Ellis Hermydio Figueira, 783, Bloco A, sl. 218, Aterrado. \\
27213-415 - Volta Redonda, RJ - Brasil \\
www.uff.br \\
\hline Copyright (C) 2017 RASI. Todos os direitos, até mesmo de tradução, são reservados. É \\
permitido citar parte de artigos sem autorização prévia, desde que seja identificada a fonte \\
\hline
\end{tabular}




\section{Avaliação de aspectos e atributos de sustentabilidade para priorização de projetos de dragagem em portos}

\section{Introdução}

As atividades portuárias são essenciais para o desenvolvimento econômico dos países (ou regiões específicas), pois movimentam cerca de $80 \%$ do volume de comércio mundial (Smith et al., 2015; UNCTAD, 2016). No Brasil, foram movimentadas cerca de 970 milhões de toneladas em 2014, representando um acréscimo de 9,4\% em relação a 2011 (ANTAQ, 2011 e 2015).

Dada a relevância do sistema portuário para a economia brasileira, o governo federal busca a integração dos sistemas de transporte de forma a aumentar o dinamismo e competitividade das cadeias produtivas do país. Assim, alguns estudos governamentais de cunho estratégico têm sido desenvolvidos, tais como: Plano Nacional de Logística e Transporte - PNLT (MT 2007 e 2009), Plano Geral de Outorgas do Setor Portuário - PGO (ANTAQ, 2009) e o Plano Nacional de Logística Portuária - PNLP (SEP, 2012).

No entanto, devido à diversidade geográfica das zonas de demanda e produção brasileiras é necessário estudar como tornar compatível a estrutura do porto com a dinâmica da movimentação de carga. Além disso, a crescente demanda por transporte marítimo exige o uso de maiores embarcações para se alcançar economias de escala (Ports Australia, 2014; Lukens, 2000).

Para a redução do valor unitário do frete das cargas em função do aumento dos navios (Stopford, 2008) é necessário que a infraestrutura portuária seja adaptada para recebê-los. Nesse sentido os gestores portuários demandam canais de acesso mais profundos para que seja possível receber esses tipos navios. A alternativa para isso é a realização da dragagem do canal de acesso portuário para rebaixamento do leito.

Para a realização da dragagem são necessários equipamentos específicos e técnicas especializadas (Fadda, 2012) o que implica em custos relevantes tanto para o planejamento quanto para a execução (Lukens, 2000). Ainda, um processo de dragagem pode causar impactos econômicos, sociais e ambientais positivos e negativos.

Do ponto de vista econômico, a renda líquida tende a crescer devido ao aumento da demanda associada à oportunidade de se receber navios maiores que transportam maior quantidade carga. Além disso, a demanda existente pode ser atendida sem comprometer a segurança da navegação.

Considerando o aspecto ambiental, tanto o processo de dragagem como o tratamento ou disposição do material dragado podem afetar negativamente a saúde humana e o habitat de outras espécies. Em relação ao aspecto social, a comunidade do entorno de um porto dragado pode sofrer impactos relativos a questões culturais, recreativas e nas demais atividades locais. Portanto, a seleção dos portos a serem dragados deve ser feita considerando, no mínimo, os aspectos econômico, social e ambiental.

Dentre a bibliografia pesquisada destaca-se o trabalho de Guimarães et al. (2016) que apresenta resultados que norteiam a tomada de decisão para priorização de dragagem, considerando os atributos associados aos aspectos econômico, social, ambiental, técnico, legal e político. Os autores consideraram a opinião de um grupo de especialistas quanto à importância desses atributos e utilizaram uma técnica de apoio multicritério à decisão para tratamento dos dados.

Nesse sentido, dada a demanda por dragagem proveniente dos diferentes portos de um país (ou região), os recursos limitados do governo (e/ou agentes privados) e os impactos 
resultantes do processo de dragagem (em termos sociais, ambientais, econômicos etc) surge a seguinte pergunta: quais os aspectos e atributos seriam mais relevantes para priorizar os portos a serem dragados na visão dos diferentes grupos que compõem os stakeholders?

Assim, neste artigo pretende-se avaliar a importância de um conjunto de aspectos e atributos a eles vinculados - considerados os mais relevantes pelos diferentes grupos que compõem os stakeholders (especificamente, especialistas do governo, universidades e empresas) - para priorizar os portos a serem dragados. Como objetivos específicos, têm-se: (i) identificar os aspectos e atributos relacionados à dragagem por meio de literatura nacional e internacional; (ii) estabelecer a importância dos aspectos e atributos com base na opinião dos diferentes grupos relacionados aos stakeholders e com a utilização de uma técnica multicritério; (iii) comparar a visão dos diferentes grupos envolvidos com dragagem no Brasil.

A consulta a especialistas pertencentes aos diferentes grupos que formam os stakeholders, realizada neste artigo em complemento a pesquisa de Guimarães et al. (2016), é uma forma adequada para se identificar o grau de importância dos atributos considerando as perspectivas de embarcadores, transportadores, operadores portuários, governo (autoridade portuária), instituições de pesquisa como universidades etc.

No que diz respeito à relevância deste tema, acredita-se que este artigo contribuirá para as políticas do governo federal, uma vez que esses aspectos e atributos podem ser utilizados como ferramenta de apoio ao planejamento de intervenções públicas e privadas na infraestrutura portuária.

A partir desta introdução este artigo foi estruturado da seguinte forma: a seção 2 apresenta os conceitos sobre dragagem em portos marítimos e sobre aspectos e atributos associados que serviram de base para este artigo; na seção 3 está descrita a metodologia utilizada na condução da pesquisa; os resultados estão apresentados na seção 4 que é seguida da seção 5 (considerações finais) e, por fim, a lista de referências utilizadas para a realização da pesquisa.

\section{Drenagem em portos marítimos}

O serviço de transporte marítimo abrange o atendimento de movimentação de cargas dentro de condições pré-determinadas. O setor portuário é responsável por conduzir as mais diversas cargas ao seu destino final. Por isso são considerados importantes elos na cadeia de suprimentos, sendo fator importante para o desenvolvimento de um país.

De acordo com a ANTAQ (2015), a movimentação de cargas nos portos brasileiros bateu recorde em 2015, superando 1 bilhão de toneladas, volume 3,9\% acima da movimentação de 2014. Entretanto, em 2016 houve decréscimo na movimentação de carga nos portos de $2,5 \%$ em relação ao ano anterior.

Segundo o diagnóstico dos portos brasileiros (Fórum de Direito Marítimo, Portuário e Logística do Estado do Ceará, 2012), um dos gargalos para a expansão do transporte marítimo no Brasil são os canais de acesso, bacias de evolução e berços de atracação. A solução para este problema seria a dragagem de aprofundamento, com o objetivo de adequar o país à sua realidade atual e futura, tanto no cenário nacional como internacional. Isso poderia auxiliar na redução da estadia de navios, no aumento da competitividade e na redução de custo nacional.

Castro (2012) explica que a dragagem é realizada para limpeza, desobstrução, remoção, derrocamento ou escavação de material do fundo de rios, lagos, mares, baías e canais, removendo rochas e sedimentos e lançadas em local de despejo. Alfredini e Arasaki (2014) complementam que ela é realizada por meio de equipamentos mecânicos e hidráulicos, 
considerando aspectos técnicos, econômicos e ambientais. Essa é uma necessidade não somente para implantação, aprofundamento ou manutenção, mas também para a remediação, que tem como propósito limpar e recuperar áreas com sedimentos contaminados.

Conforme descrito pela Secretaria Especial de Portos (SEP), o Programa Nacional de Dragagem (PND), instituído pela Lei 11.610/2007, foi criado para propor e desenvolver soluções para reduzir os gargalos que limitam os acessos marítimos aos portos brasileiros. De acordo com o PND II (SEP, 2014), os gastos projetados para 2016/17 no Programa de Investimentos de Dragagem superam os $\mathrm{R} \$ 23$ bilhões. O programa visa à expansão da infraestrutura dos portos, com o objetivo de aumentar da eficiência para atingir reduções de custos e atrair investimentos para aumento da capacidade que possa absorver a demanda crescente. Entretanto, esses valores seriam divididos em projetos de 25 portos, nos diferentes estados da federação. Assim, verifica-se que os projetos de dragagem envolvem volumes de recursos que requerem a priorização das demandas, dado que não seria possível realizar todo o investimento ao mesmo tempo.

Para estruturação desta pesquisa utilizaram-se os conceitos de aspectos e atributos, conforme Leal Jr (2010). O autor considera que um atributo é uma qualidade ou característica associada a um elemento que se está analisando ou avaliando. Os atributos são genéricos e podem representar ideias diferentes, dependendo de quem os interpreta. Já os aspectos se constituem como conjunto de atributos que tem características próximas e que podem ser agrupados segundo sua natureza.

Guimarães et al. (2016), com base em Bebiano et al. (2015), Colier et al. (2014), Secretaria Especial de Portos (2014), Scheffler, Roth e Ahlf (2014), Alfredini e Arasaki (2014), Manap e Voulvoulis (2014), Vikolainen et al. (2014), Agunwamba, Onuoha e Okoye (2012), Lobedan et al. (2012), Sheehana e Harrington (2012), Fettweis et al. (2011), Kapsimalis et al. (2010), Alvarez-Guerra et al. (2007), Angonesi et al. (2006), Marine SACs Project (2006), Kiker et al. (2005) e Lukens (2000) identificaram seis aspectos e os três principais atributos relacionados a cada um deles, que podem ser utilizados para priorizar projetos de dragagem (conforme Tabela 1). Ressalta-se que esta definição foi realizada pelos autores com base no que foi levantado em pesquisa bibliográfica.

Tabela 1: Aspectos e atributos para priorização de portos para dragagem

\begin{tabular}{|c|c|c|c|c|}
\hline Aspecto & Descrição do aspecto & Atributo & Descrição do atributo & $\overline{\mathrm{FL}}$ \\
\hline \multirow[t]{3}{*}{ Econômico } & \multirow{3}{*}{$\begin{array}{l}\text { Relacionado } \\
\text { questões financeiras } \\
\text { dos projetos de } \\
\text { dragagem bem como } \\
\text { aos impactos } \\
\text { econômicos positivos } \\
\text { e negativos em níveis } \\
\text { local, regional e } \\
\text { nacional. }\end{array}$} & $\begin{array}{l}\text { Custo } \\
\text { Benefício }\end{array}$ & $\begin{array}{l}\text { Abrange os investimentos, custos e despesas } \\
\text { para se realizar a dragagem em relação aos } \\
\text { benefícios econômicos gerados de curto, médio } \\
\text { e longo prazo. Inclui também os benefícios de } \\
\text { redução de custos logísticos, operação portuária } \\
\text { e aumento da competitividade. }\end{array}$ & 11 \\
\hline & & $\begin{array}{l}\text { Atividade } \\
\text { econômica } \\
\text { relacionada }\end{array}$ & $\begin{array}{l}\text { Relaciona-se aos impactos gerados nas } \\
\text { atividades econômicas que dependem da } \\
\text { dragagem direta ou indiretamente, como: } \\
\text { transporte de carga e passageiros, turismo, } \\
\text { pesca, lazer, escoamento da produção } \\
\text { industrial. }\end{array}$ & 14 \\
\hline & & $\begin{array}{l}\text { Movimentaçã } \\
\text { o e impacto da } \\
\text { economia } \\
\text { local } \\
\text { regional }\end{array}$ & $\begin{array}{l}\text { Refere-se a impactos econômicos na região } \\
\text { onde a dragagem é realizada, tais como: nível } \\
\text { de emprego para a população local, influência } \\
\text { no PIB da região, mercado imobiliário, } \\
\text { oportunidades de novos negócios ou extinção } \\
\text { dos existentes. }\end{array}$ & 9 \\
\hline Social & Refere-se aos efeitos & Aceitação & Envolve questões relacionadas à receptividade & 4 \\
\hline
\end{tabular}




\begin{tabular}{|c|c|c|c|c|}
\hline Aspecto & Descrição do aspecto & Atributo & Descrição do atributo & $\mathrm{FL}^{\mathrm{T}}$ \\
\hline \multirow{3}{*}{ Aspecto } & \multirow{3}{*}{$\begin{array}{l}\text { sociais associados a } \\
\text { realização da } \\
\text { dragagem em um } \\
\text { porto. Esses efeitos } \\
\text { podem desde as } \\
\text { interações sociais da } \\
\text { comunidade local, } \\
\text { passando por } \\
\text { relações } \\
\text { interinstitucionais até } \\
\text { questões relacionadas } \\
\text { com alterações no } \\
\text { tipo de trabalho e } \\
\text { emprego, saúde e } \\
\text { cultura da população. }\end{array}$} & pública & $\begin{array}{l}\text { da comunidade local do projeto de dragagem. A } \\
\text { aceitação pública pode estar relacionada a } \\
\text { possíveis impactos na qualidade de vida. }\end{array}$ & \\
\hline & & $\begin{array}{ll}\text { Alteração } & \text { de } \\
\text { tipo } & \text { de } \\
\text { emprego } & \end{array}$ & $\begin{array}{l}\text { As atividades laborais da população podem ser } \\
\text { alteradas em função da dragagem que pode } \\
\text { restringir as atividades atuais (impacto na } \\
\text { piscicultura) e/ou incentivar outras relacionadas } \\
\text { diretamente à atividade portuária (turismo, } \\
\text { transporte, logística, estiva). }\end{array}$ & 4 \\
\hline & & $\begin{array}{ll}\text { Saúde } & \text { da } \\
\text { população } & \end{array}$ & $\begin{array}{l}\text { Relaciona-se aos efeitos diretos e indiretos à } \\
\text { saúde humana decorrentes da dragagem com } \\
\text { relação à disposição do material dragado, } \\
\text { qualidade da água, exposição a sedimentos } \\
\text { nocivos. }\end{array}$ & 5 \\
\hline \multirow[t]{3}{*}{ Técnico } & \multirow{3}{*}{$\begin{array}{l}\text { Relacionado a } \\
\text { características } \\
\text { técnicas dos projetos } \\
\text { de dragagem. } \\
\text { Envolve a magnitude } \\
\text { da dragagem, } \\
\text { métodos e técnicas } \\
\text { para dragagem e seu } \\
\text { gerenciamento, riscos } \\
\text { do projeto, } \\
\text { características físicas } \\
\text { e ambientais da } \\
\text { região dragada e seu } \\
\text { entorno, tipo e forma } \\
\text { de destinação dos } \\
\text { sedimentos. }\end{array}$} & $\begin{array}{ll}\text { Método } & \text { de } \\
\text { dragagem }\end{array}$ & $\begin{array}{l}\text { O método de dragagem se refere às técnicas } \\
\text { para retirada, forma e local para disposição dos } \\
\text { sedimentos, equipamentos e demais recursos a } \\
\text { serem utilizados, além da tecnologia de } \\
\text { controle e gerenciamento da atividade e } \\
\text { viabilidade da obra. }\end{array}$ & 10 \\
\hline & & $\begin{array}{l}\text { Características } \\
\text { físicas e } \\
\text { ambientais }\end{array}$ & $\begin{array}{l}\text { Engloba características físicas do local } \\
\text { (correntes marinhas, amplitude das marés, } \\
\text { densidade da água, direção e velocidade das } \\
\text { correntes, leito marinho, estado do canal, } \\
\text { integração de rio com mar) e do material a ser } \\
\text { dragado (tipo, nível de contaminação e local de } \\
\text { despejo do sedimento). }\end{array}$ & 11 \\
\hline & & $\begin{array}{l}\text { Sedimentos } \\
\text { gerados }\end{array}$ & $\begin{array}{l}\text { Refere-se às características físicas e químicas } \\
\text { do sedimento, seleção do local de despejo e sua } \\
\text { distância, tipo de tratamento, nível de } \\
\text { contaminação dos sedimentos dragados. }\end{array}$ & 21 \\
\hline \multirow[t]{3}{*}{ Ambiental } & \multirow{3}{*}{$\begin{array}{l}\text { Envolve questões } \\
\text { ambientais } \\
\text { decorrentes } \\
\text { dragagem e qu } \\
\text { trazem impactos, de } \\
\text { diferentes } \\
\text { magnitudes, à vida } \\
\text { das pessoas e } \\
\text { espécies marinhas e } \\
\text { de outros biomas. }\end{array}$} & $\begin{array}{l}\text { Qualidade da } \\
\text { água }\end{array}$ & $\begin{array}{l}\text { A qualidade da água está relacionada às } \\
\text { alterações de suas características em função da } \\
\text { dragagem, tais como: contaminação por } \\
\text { sedimentos, turbidez, grau de salinidade, } \\
\text { temperatura, ph, interferência na transmissão da } \\
\text { luz etc. Também se relaciona com a alteração } \\
\text { da hidrodinâmica. }\end{array}$ & 18 \\
\hline & & Vida marinha & $\begin{array}{l}\text { Este atributo abrange os impactos provenientes } \\
\text { da dragagem na vida marinha incluindo: a } \\
\text { modificação dos habitats, saúde das espécies, } \\
\text { mutação ou extinção de espécies marinhas, } \\
\text { favorecimento de espécies não-nativas etc. }\end{array}$ & 18 \\
\hline & & $\begin{array}{ll}\text { Vida } & \text { fora } \\
\text { d'água } & \end{array}$ & $\begin{array}{l}\text { Abrange os impactos provenientes da dragagem } \\
\text { na vida fora da água (fauna e flora). Esses } \\
\text { impactos podem ser decorrentes de alterações } \\
\text { na vida marinha ou em função de despejo de } \\
\text { sedimentos em terra, por exemplo, aterros e } \\
\text { mangues. }\end{array}$ & 14 \\
\hline \multirow[t]{3}{*}{ Legal } & \multirow{3}{*}{$\begin{array}{l}\text { Inclui o conjunto de } \\
\text { leis, normas e } \\
\text { tratados que tenham } \\
\text { relação com a } \\
\text { dragagem, que } \\
\text { possam impactar no }\end{array}$} & $\begin{array}{l}\text { Legislação } \\
\text { nacional }\end{array}$ & $\begin{array}{l}\text { Refere-se aos requisitos legais para dragagem } \\
\text { provenientes de legislação brasileira. }\end{array}$ & 3 \\
\hline & & $\begin{array}{l}\text { Legislação } \\
\text { internacional }\end{array}$ & $\begin{array}{l}\text { Abrange os requisitos legais para dragagem } \\
\text { baseados em legislação internacional, tratados, } \\
\text { convenções, normas, entre outros. }\end{array}$ & 8 \\
\hline & & Legislação & Incluem-se aqui as leis ambientais que não & 5 \\
\hline
\end{tabular}




\begin{tabular}{|c|c|c|c|c|}
\hline Aspecto & Descrição do aspecto & Atributo & Descrição do atributo & $\mathrm{FL}^{\mathrm{T}}$ \\
\hline & $\begin{array}{l}\text { projeto e imponham } \\
\text { necessidades de } \\
\text { conformidade legal. }\end{array}$ & $\begin{array}{l}\text { ambiental } \\
\text { específica }\end{array}$ & $\begin{array}{l}\text { estão, necessariamente, relacionadas à } \\
\text { dragagem, mas que influenciam na gestão dos } \\
\text { projetos desde o planejamento até a conclusão } \\
\text { das obras. }\end{array}$ & \\
\hline \multirow[t]{3}{*}{ Político } & \multirow{3}{*}{$\begin{array}{l}\text { Refere-se a questões } \\
\text { políticas que passam } \\
\text { por relacionamento } \\
\text { entre governos } \\
\text { municipais, estaduais } \\
\text { e federal, formas de } \\
\text { financiamento } \\
\text { público aos projetos } \\
\text { de dragagem e } \\
\text { relações } \\
\text { licenciamento, para } \\
\text { mediação } \\
\text { conflitos e diálogo na } \\
\text { solução de conflitos } \\
\text { com a sociedade. }\end{array}$} & $\begin{array}{l}\text { Financiament } \\
\mathrm{o}\end{array}$ & $\begin{array}{l}\text { Este atributo refere-se a definições políticas a } \\
\text { respeito da responsabilidade pelo financiamento } \\
\text { e custeio das obras de dragagem que podem ser } \\
\text { realizados pela iniciativa privada (concessão), } \\
\text { parceria público-privada, ou até mesmo pelo } \\
\text { próprio governo. }\end{array}$ & 2 \\
\hline & & $\begin{array}{l}\text { Relacionamen } \\
\text { to entre } \\
\text { governos }\end{array}$ & $\begin{array}{l}\text { Abrange os arranjos políticos e institucionais de } \\
\text { forma a promover o relacionamento entre } \\
\text { governos municipais, estaduais e federal e } \\
\text { sociedade com foco na discussão dos projetos } \\
\text { de dragagem. }\end{array}$ & 1 \\
\hline & & $\begin{array}{lr}\text { Mediação } & \text { de } \\
\text { conflitos } & \mathrm{e} \\
\text { interesses } & \end{array}$ & $\begin{array}{l}\text { Refere-se ao papel das entidades } \\
\text { governamentais para mediação e diálogo na } \\
\text { solução de conflitos decorrentes da dragagem, } \\
\text { bem como na promoção de mecanismos de } \\
\text { interação social e licenciamento ambiental } \\
\text { (audiência pública). }\end{array}$ & 1 \\
\hline
\end{tabular}

Nota. (1) FL = Frequência na literatura

Por meio da Tabela 1 é possível verificar diversidade de atributos na literatura pesquisada, cabendo ressaltar que muitos dos que estão apresentados tem nomenclatura diferente nos trabalhos levantados. Por isso, foi necessária a padronização dos nomes dos atributos segundo suas definições.

Como a quantidade de aspectos e atributos pesquisados para a tomada de decisão na priorização dos portos para dragagem é grande, Gomes (2004) e Leal Jr (2010) recomendam a atribuição de pesos: (i) com base na experiência do tomador de decisão, (ii) por meio da frequência de citações no referencial teórico pesquisado ou (iii) por meio de consulta a especialistas.

Guimarães et al. (2016) aplicaram um questionário a 15 especialistas da área portuária para verificar qual seria a importância dos atributos apresentados na decisão por priorização de projetos de dragagem. $\mathrm{O}$ tratamento dos dados foi feito utilizando-se a técnica multicritério AHP - Analytic Hierarchy Process (Saaty, 1980). Além disso, com base na Tabela 1, verificaram a frequência de citações de cada atributo na literatura pesquisada, sendo possível apresentar a Figura 1. 


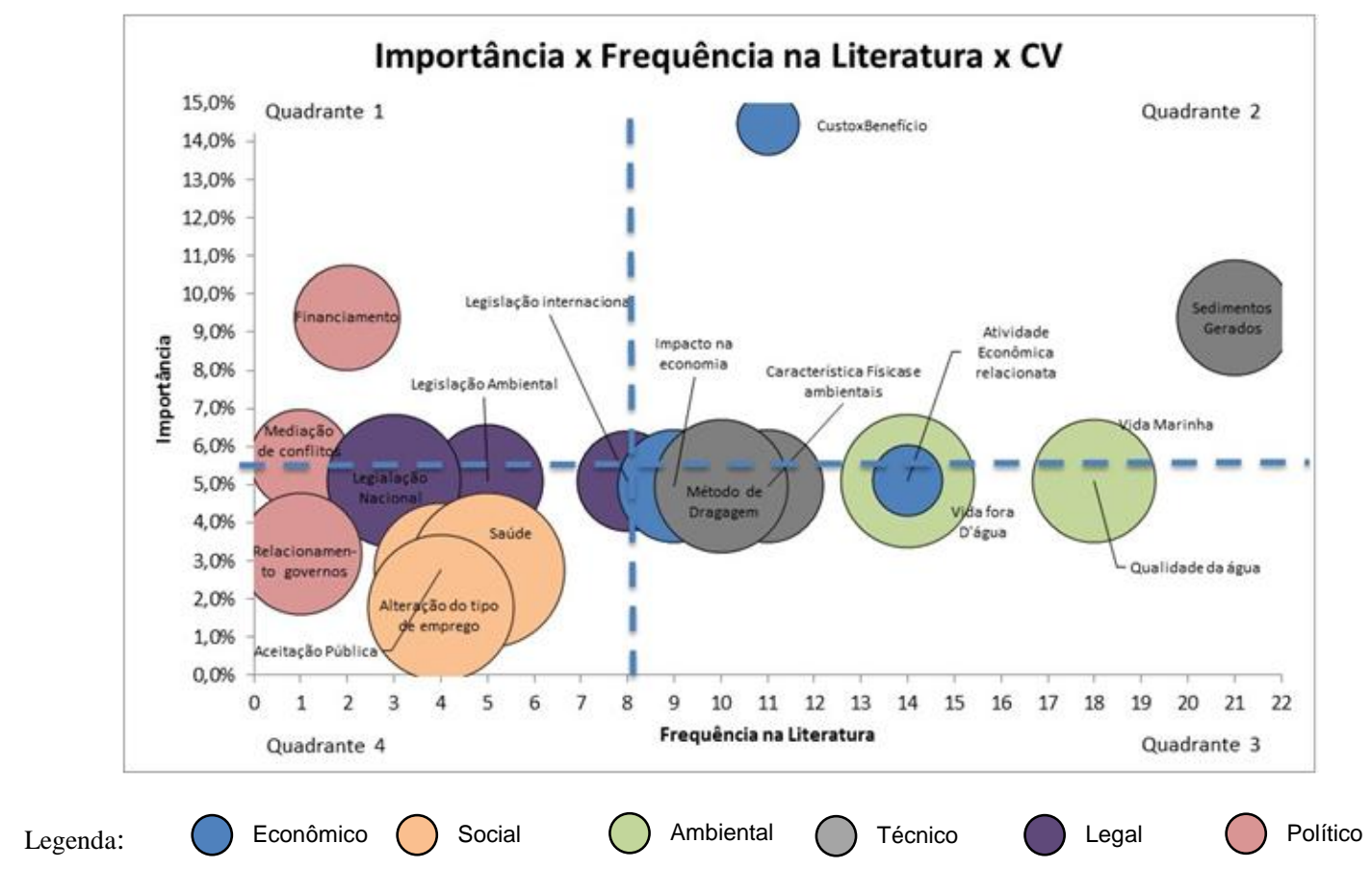

Figura 1. Aspectos e atributos analisados em Guimarães et al. 2016

Por meio da Figura 1 visualizam-se, além da importância atribuída pelos especialistas e a frequência na literatura, o coeficiente de variação - CV - das notas dos referidos especialistas a cada atributo (representado pelo tamanho dos círculos - quanto maior o círculo maior o CV). Além disso, é possível identificar a disposição dos atributos (representados por cores) em quatro quadrantes que foram formados considerando a média da importância dos atributos e a mediana da frequência na literatura.

Verifica-se que os atributos com a menor variação nas respostas dos especialistas são os ligados ao aspecto econômico. Os atributos do aspecto social, ao contrário, são aqueles com maior CV. Além de serem os menos importantes na visão dos especialistas e estarem entre os menos citados na literatura, nota-se que não há consenso na avaliação. Talvez isso aconteça, pois os próprios especialistas não têm certeza do nível de importância do aspecto social, justamente por ser um tema pouco discutido.

Constata-se, ainda, pela Figura 1, a concentração dos aspectos sociais, políticos e legais no quadrante quatro, sendo que os dois últimos possuem menor $\mathrm{CV}$, considerando o conjunto de respostas dos especialistas. Destaca-se o atributo de legislação nacional com o maior CV no aspecto legal. Isso pode ter acontecido em função da dragagem obedecer a muitas convenções e normas internacionais e a própria legislação ambiental específica se confundir com a legislação nacional.

No terceiro quadrante estão todos os atributos ambientais, dois técnicos e dois econômicos, sendo que o "método de dragagem", "vida fora d'água" e "vida marinha" apresentam menor consenso nas respostas dos especialistas. O Quadrante 2 contém dois dos principais atributos da pesquisa realizada, incluindo o "Custo x Benefício" que possui ainda o maior consenso sobre sua importância (menor CV). Além disso, neste quadrante encontra-se o atributo mais citado na bibliografia.

Por fim, no primeiro quadrante, encontra-se o "financiamento", sendo considerado de baixa frequência na literatura pesquisada, mas de alta importância pelos especialistas. Este atributo apresenta também o quarto menor $\mathrm{CV}$ da pesquisa. 
Neste sentido, torna-se importante avaliar a opinião por grupo de especialistas para tentar compreender se há um consenso entre os diferentes stakeholders envolvidos no processo sobre os atributos relevantes para se priorizar os portos a serem dragados.

\section{Procedimentos Metodológicos}

Para a realização deste artigo foram feitas pesquisas: (i) bibliográfica - para selecionar os artigos que abordavam o assunto em questão e entender os conceitos relacionados ao tema de estudo; e (ii) documental - para aperfeiçoar o conhecimento sobre os programas de governo que vem sendo desenvolvidos. Por meio das duas pesquisas foram levantados os aspectos e atributos envolvidos no processo de priorização de portos para dragagem.

Em seguida, foi possível realizar a padronização dos termos mais utilizados pelos autores sobre o assunto estudado bem como a conceituação de cada aspecto e atributo, conforme Guimarães et al. (2016). Para atribuição do grau de importância dos aspectos e atributos podem ser utilizadas técnicas de auxílio multicritério à decisão, as quais se embasam em experiência de especialistas, para de forma empírica e por meio de suas opiniões, quantifiquem os resultados (Gomes, 2004).

Assim, com o entendimento do conceito de cada aspecto e atributo, foi necessária a coleta de opinião de especialistas quanto à importância de cada um deles no processo de priorização de portos para dragagem. Para isto, foi desenvolvido um questionário, que foi enviado por meio da ferramenta Google Docs, cujos resultados foram tratados utilizando a AHP (Saaty, 1980).

Segundo Gomes e Lima (1992) e Gomes (2004) a AHP é uma das técnicas de auxílio multicritério à decisão mais utilizadas, onde o problema de decisão é dividido em níveis hierárquicos, facilitando, assim, sua compreensão e avaliação.

$\mathrm{Na}$ AHP, um grupo de decisores formados por especialistas devem fazer uma comparação, par a par, de cada elemento, criando-se uma matriz de decisão quadrada. A comparação das alternativas é realizada com o auxílio de uma escala verbal associada a uma escala numérica que varia de 1 a 9, sendo: 1 para igualmente preferível, 3 para moderadamente preferível, 5 para fortemente preferível, 7 para muito fortemente preferível e 9 para extremamente preferível. Os valores 2, 4, 6 e 8 são considerados como importantes intermediários (Saaty, 1980).

Uma medida de inconsistência é obtida por meio do cálculo do autovetor. Dessa forma, sendo $a_{i j} \mathrm{O}$ valor obtido da comparação par a par do elemento i com o elemento j, a matriz formada por esses valores é a matriz $A$, onde $A=\left(a_{i j}\right)$. A matriz A é recíproca tal que $a_{j i}=1 / a_{i j}$, na qual, se os juízos fossem perfeitos, em todas as comparações seria possível verificar que $a_{i j} x a_{j k}=a_{i k}$ para qualquer $i, j, k$.

Caso os juízos emitidos pelos decisores sejam perfeitamente consistentes, têm-se $\lambda_{\max }($ autovetor $)=n$ e $a_{i j}=w_{i} / w_{j}$. Contudo, pode-se verificar uma inconsistência nos juízos, que pode ser medida pela proximidade de $\lambda_{\max } \operatorname{com} \mathrm{n}$ (quanto mais próximo, maior a consistência). Portanto, $\lambda_{\max }-n$ é um indicador da consistência (Gomes, 2004). Para obter o autovetor aplica-se a Equação 1.

$$
\lambda_{\max }=\frac{1}{n} \sum_{i=1}^{n} w_{i} \frac{A w_{i}}{w_{i}}
$$

Onde: $A w=\lambda_{\max } \times w$ e $n$ corresponde ao número de alternativas ou elementos comparados. 
Segundo Saaty (1980), existem pequenas variações em $a_{i j}$ que implicam pequenas variações em $\lambda_{\max }$, em que o desvio do autovetor em relação a $n$ é considerado uma consistência. Por isso, é possível afirmar, através do Índice de Consistência (IC), que $\lambda_{\max }$ permite avaliar a proximidade da escala desenvolvida por Saaty com a escala de razões ou quocientes que seria usada se a matriz A fosse totalmente consistente (Equação 2).

$$
I C=\left(\lambda_{\max }-n\right) /(n-1)
$$

A AHP admite a inconsistência como inerente ao comportamento humano. Assim, Saaty (1980) propõe o cálculo da Razão de Consistência - $R C$ (Equação 3) e indica que esta razão é considerada aceitável quando é menor ou igual a 0,10 .

$$
R C=I C / I R
$$

Onde: IC corresponde ao Índice de Consistência e IR é um índice aleatório, calculado para matrizes quadradas de ordem $\mathrm{n}$.

Utilizando a matriz de decisão $A$, o Método AHP calcula resultados parciais do conjunto $A$, dentro de cada atributo $v_{i}\left(A_{j}\right)$, denominado valor de impacto da alternativa $\mathrm{j}$ em relação à alternativa $i$, em que esses resultados representam valores numéricos das atribuições verbais dadas pelo decisor a cada comparação de alternativas. Tais resultados são normalizados pela Equação 4.

$$
\sum_{i=1}^{n} v_{i}\left(A_{j}\right)=1 j=1, \ldots, n
$$

Sendo, $v_{i}\left(A_{j}\right)=\frac{a_{i j}}{\sum_{i=1}^{n} a_{i j^{\prime}}}$

Isso faz com que o vetor de prioridades da alternativa $i$ em relação ao atributo $C_{k}$ seja:

$$
v_{i}\left(A_{j}\right)=\sum_{j=1}^{n} v_{i}\left(A_{j}\right) / n \quad i=1, \ldots, n
$$

Depois de obter o vetor de prioridades das alternativas sob cada atributo $C_{k}$, continuase com o nível de atributos. Nesse caso, adota-se novamente a escala de Saaty para a classificação par a par dos atributos, que são normalizados pela Equação 6 onde $\mathrm{m}$ corresponde ao número de atributos de um mesmo nível e o vetor prioridade é obtido pela Equação 7.

$$
\begin{array}{cc}
w_{i}\left(C_{j}\right)=\frac{c_{i j}}{\sum_{i=1}^{m} c_{i j}} & j=1, \ldots, m \\
w\left(C_{i}\right)=\sum_{j=1}^{m} w_{i} \frac{c_{j}}{m} & i=1, \ldots, m
\end{array}
$$

Para obter uma ordenação global, utiliza-se a Equação 8 para gerar os valores finais das alternativas e assim hierarquizá-las. 


$$
f\left(A_{i}\right)=\sum_{j=1}^{m} w_{i}\left(C_{i}\right) \times v_{i}\left(A_{j}\right) j=1, \ldots, n
$$

Onde: $n$ corresponde ao número de alternativas.

Assim, as opiniões de especialistas quanto à importância dos atributos foram quantificadas pela AHP por meio das Equações 1,2, 3, 6 e 7. As demais equações não foram utilizadas porque não houve avaliação de alternativas com base nos atributos estudados. Cabe ressaltar que os especialistas fizeram atribuíram notas conforme a escala de Saaty. Porém, o lançamento na matriz de comparação par a par foi realizado pelos pesquisadores, tomando como base a proporção entre as medianas do conjunto de respostas dos respondentes.

Foi realizada, ainda, uma análise dos coeficientes de variação (CV) das avaliações de cada atributo, conforme Equação 9, já que se trabalhou com uma escala intervalar para resposta dos questionários (Estes e Kuespert, 1976). Quanto menor o CV, maior é o consenso entre os respondentes na atribuição de importância em um dado atributo.

$$
C V_{3}=\frac{Q_{3}-Q_{1}}{M}
$$

Onde: $Q_{3}=$ Terceiro quartil, $Q_{1}=$ Primeiro Quartil e $M=$ Mediana dos resultados

As respostas foram analisadas considerando a opinião de cada grupo de especialistas que compõem os stakeholders. Assim, foi possível comparar a visão dos grupos quanto à importância de cada aspecto e atributo levantado na literatura.

\section{Seleção e Priorização de Aspectos e Atributos de Dragagem}

Com a aplicação do questionário, foram recebidas 28 respostas de três diferentes grupos stakeholders, sendo: 39,3\% acadêmicos, 32,3\% da área governamental e 28,5\% que atuam em empresas. A caracterização dos respondentes de cada grupo está apresentada na Tabela 2.

Tabela 2: Caracterização dos respondentes, por tipo de stakeholder

\begin{tabular}{|l|c|c|c|c|}
\hline Características & Academia & Empresa & Governo & Geral \\
\hline Idade média dos respondentes & 48 & 46 & 40 & 44 \\
\hline Tempo médio de experiência em transportes (em anos) & 13 & 22 & 13 & 14 \\
\hline Tempo médio de experiência com portos (em anos) & 8 & 12 & 9 & 9,5 \\
\hline Tempo médio de experiência com dragagem (em anos) & 5 & 7 & 7 & 6,3 \\
\hline Estados em que atuam profissionalmente & $\begin{array}{c}\text { RJ, SP, MA, } \\
\text { AM }\end{array}$ & RJ, ES, SP & $\begin{array}{c}\text { DF, RJ, SP, } \\
\text { MA }\end{array}$ & - \\
\hline $\begin{array}{l}\text { Grau de pertinência do assunto pesquisado (mediana em } \\
\text { escala de 1 a 7) }\end{array}$ & 6 & 6 & 6 & 6 \\
\hline $\begin{array}{l}\text { Coeficiente de variação em relação à pertinência da } \\
\text { pesquisa }\end{array}$ & $14,1 \%$ & $16,3 \%$ & $14,4 \%$ & $14,9 \%$ \\
\hline
\end{tabular}

Com base na Tabela 2, nota-se que os entrevistados são, de fato, especialistas na área e que os grupos possuem experiência semelhante ao se observar o tempo médio de atuação e idade. Além disso, verifica-se que a pertinência da investigação conduzida neste trabalho é considerada alta pelos stakeholders entrevistados (com variação inferior a $17 \%$ na nota atribuída a esta questão). 
Inicialmente, os respondentes foram questionados sobre a importância de cada aspecto em avaliação: ambiental, econômico, legal, político, social e técnico. Os resultados estão apresentados na Figura 2.

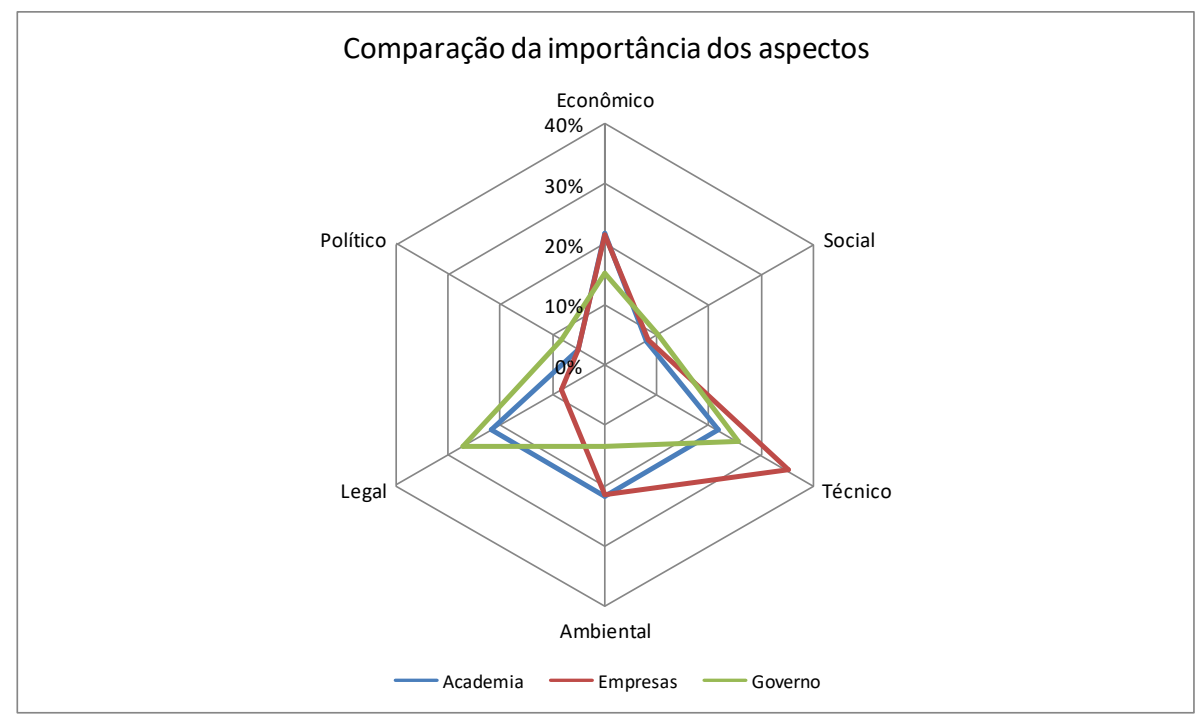

Figura 2. Importância relativa dos aspectos, por grupo de stakeholders

Verifica-se que, na opinião dos acadêmicos, os aspectos econômico, técnico, ambiental e legal têm a mesma importância (com mediana igual a 9 e importância relativa IR equivalente a 22\%). Em seguida, têm-se o aspecto social (mediana 7 e IR $8 \%$ ) e o político (mediana 6 e IR 5\%). Salienta-se, contudo, que o aspecto técnico apresentou o menor coeficiente de variação - CV entre as notas a ele atribuídas $(6 \%)$, seguido pelo econômico e ambiental (11\%, cada), legal $(17 \%)$, político $(25 \%)$ e social $(43 \%)$. O alto coeficiente de variação do aspecto social reflete a própria dificuldade em mensurar e identificar os impactos relacionados a esta dimensão.

Já os stakeholders provenientes de empresa consideram o fator técnico como mais relevante (mediana 9 e IR 35\%). Em seguida, estão empatados os aspectos econômicos e ambientais (mediana 8 e IR 22\%), bem como o legal e o social (mediana 6 e IR 8\%). Por fim, têm-se o aspecto político (mediana 5 e IR 5\%). Em relação ao $\mathrm{CV}$, o aspecto técnico foi aquele que apresentou menor índice (15\%), seguido pelo econômico (25\%) e social $(33 \%)$.

Os aspectos ambiental, legal e político, por sua vez, apresentaram um CV muito elevado $(50 \%, 50 \%$ e $57 \%$, respectivamente). Isso pode estar associado ao fato dos estudos de viabilidade para execução de projetos de infraestrutura considerarem, majoritariamente, os aspectos técnicos, econômicos e ambientais (como definido pelo próprio nome: EVTEAs Estudos de Viabilidade Técnica, Financeira e Ambiental). Dessa forma, estes stakeholders estariam mais acostumados a trabalhar com tais dimensões, apresentando dificuldade em compreender as demais (embora o aspecto legal deva nortear todas as atividades da empresa, por exemplo).

Isso mostra que também existe uma dificuldade na interpretação, por parte dos respondentes, do que deveria ser priorizado durante as operações de dragagem. A dispersão das respostas retrata um dos principais problemas do dia a dia operacional do gestor portuário envolvido no processo de dragagem. Isso porque devem-se respeitar os aspectos legais, bem como, controlar os impactos gerados ao meio ambiente e lidar com os aspectos políticos desta operação. 
Em relação aos atores governamentais, verifica-se maior ênfase nos aspectos legal (mediana 9 e IR 27\%) e técnico (mediana 9 e IR 26\%). Em seguida, têm-se os aspectos econômico (mediana 8 e IR 15\%), ambiental (mediana 8 e IR 13\%), social (mediana 7 e IR $10 \%$ ) e político (mediana 7 e IR 8\%). Diferente dos grupos anterior, o fator com menor coeficiente de variação foi o legal $(11 \%)$, o que pode estar associado diretamente à forma de atuação deste grupo (em agências reguladoras, por exemplo). Em seguida, têm-se o econômico (13\%), o técnico (22\%), o ambiental (25\%), o político (29\%) e o social (43\%).

Considerando que o governo define as regras sobre a dragagem no país, o aspecto legal tem maior preponderância, devido à função de fiscalização das atividades nos portos. Quando comparado com o stakeholder anterior fica evidente a diferença de percepção sobre a mesma atividade, entre o ente público e privado. Por sua vez, a academia apresenta uma visão mais sistêmica do processo e, por isso, todos os aspectos apresentaram pesos semelhantes.

Destaca-se que, todos os aspectos obtiveram medianas iguais ou maiores que 6 - em uma escala de 1 a 10 (com exceção do político que teve score 5 dado pelo grupo empresarial), indicando que embora haja a importância diferenciada para cada atributo, os stakeholders entendem que todos são relevantes, com grau de importância variando de médio a alto.

No que diz respeito à comparação da importância atribuída a cada aspecto por cada grupo de stakeholder com a relevância encontrada na literatura pesquisada, têm-se as Figuras 3, 4 e 5. A Figura 3 relaciona a avaliação de atores vinculados a empresas e à academia, sendo que o tamanho do círculo representa a frequência de cada aspecto na literatura.

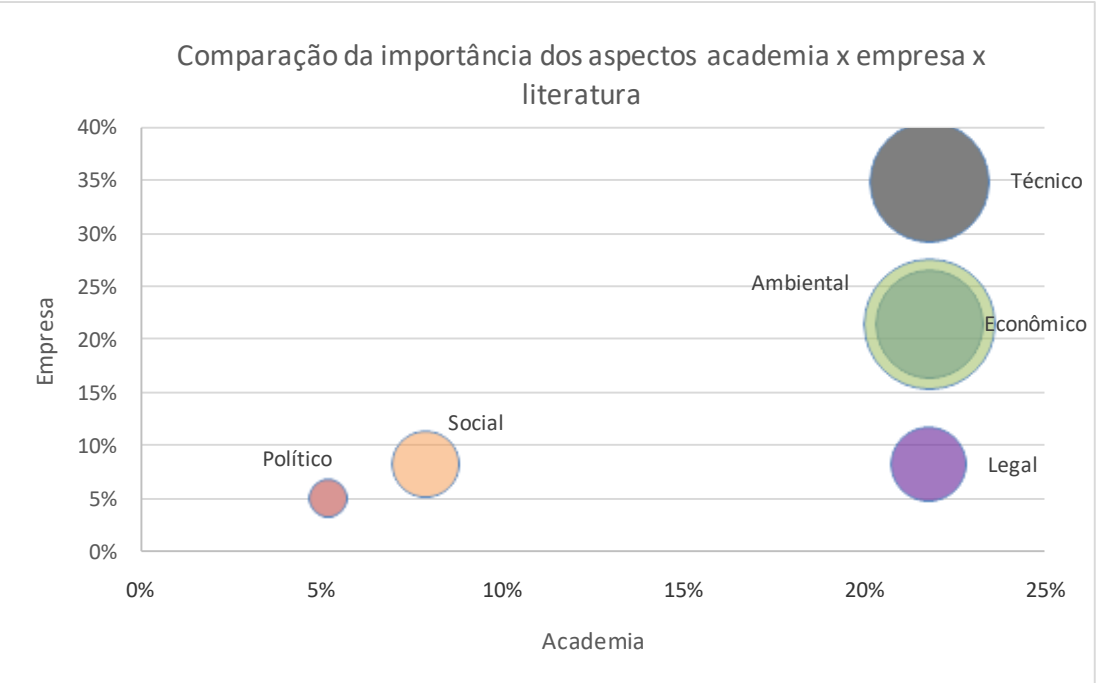

Figura 3. Importância dos aspectos - literatura x academia x empresa

Nota-se que o aspecto político é aquele com a menor quantidade de estudos encontrados (apenas quatro), bem como aquele considerado menos importante tanto pelos acadêmicos (5\%) quanto pelo empresariado (5\%). Os aspectos social e legal também tiveram uma pequena frequência na literatura (13 e 16, respectivamente). Contudo, verifica-se que, na opinião dos acadêmicos, o social (8\%) tem pouca relevância quando comparado com o legal (22\%). Já para o empresariado, tanto o social quanto o legal têm baixa importância relativa (8\%, cada). Percebe-se, portanto, divergência entre estes dois grupos quanto à importância dada ao aspecto legal. Isso pode ser justificado pelo foco de atuação de cada stakeholder no processo.

Além disso, embora o fator ambiental tenha a maior frequência na literatura, ele não foi considerado o atributo mais relevante pelos representantes de empresas (apesar de ter 
obtido um IR alto, comparado com os anteriores). Ressalta-se que os dois grupos de stakeholders atribuíram IR igual a este aspecto (22\%). Este resultado sugere que a preocupação com o meio ambiente é secundaria na prática. Quando a decisão de dragar um determinado local é tomada parte-se do princípio que o impacto ambiente será inerente no processo. Além disso, os estudos como EIA-RIMA já deverão prever os impactos que serão gerados durante a operação.

Em relação ao aspecto econômico, este tem a terceira maior frequência na literatura (34 artigos), a maior importância para os acadêmicos (empatado com os aspectos técnico, ambiental e legal) e a segunda maior para o empresarial (empatado com o ambiental). Por fim, verifica-se que o aspecto técnico é aquele de maior relevância para ambos os grupos, tendo também participação significativa na literatura (42 registros). A técnica pode fazer diferença na condução do processo de dragagem, bem como, no resultado final. Por isso, que este item tem uma elevada relevância para o setor empresarial. Uma dragagem bem conduzida tecnicamente tende a trazer bons resultados econômicos e operacionais para os terminais portuários.

Quanto à Figura 4, compara-se a avaliação de atores pertencentes à academia e ao governo. Verifica-se que os aspectos político e social têm o mesmo comportamento apresentado na Figura 3, sendo que stakeholders governamentais foram aqueles que atribuíram maior importância ao aspecto político (IR 8\%), dentre os três grupos investigados, embora este atributo tenha sido apontado como o menos relevante por todos os grupos.

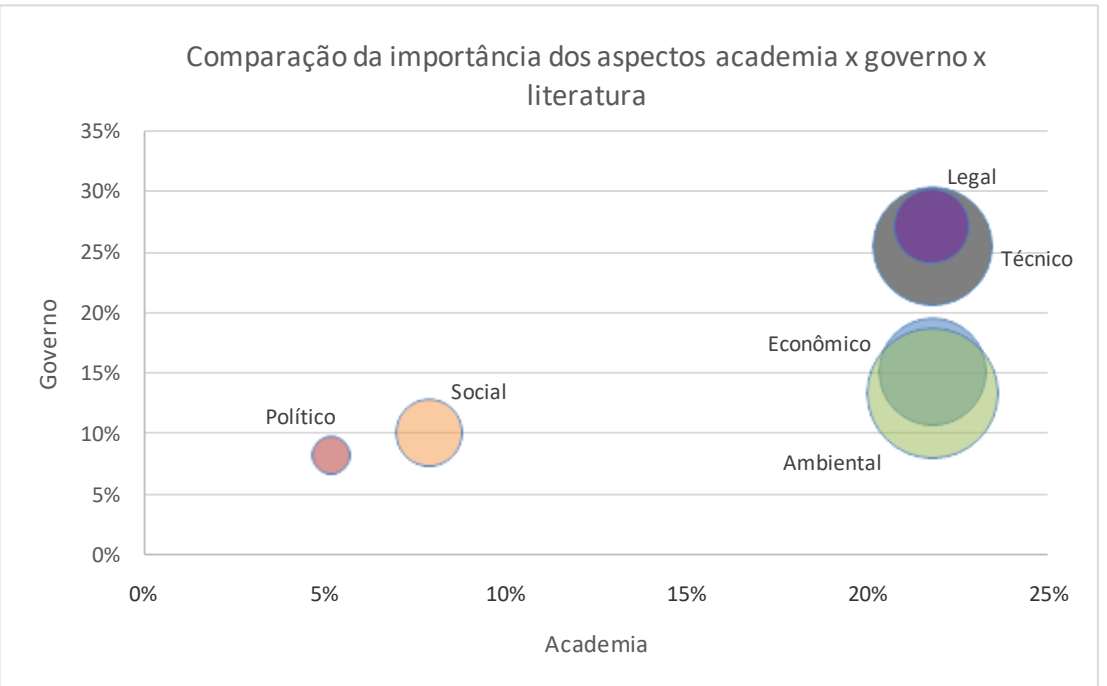

Figura 4. Importância dos aspectos - literatura $\mathrm{x}$ academia $\mathrm{x}$ governo

Além disso, percebe-se que enquanto os acadêmicos consideram os atributos ambiental, econômico, técnico e legal igualmente relevantes, os governamentais indicaram os atributos legal e técnico como mais relevantes que os ambiental e econômico. Estes resultados devem levar em consideração o fato de eventuais grupos governamentais mais ligados à questão ambiental não fazerem parte dos respondentes da pesquisa.

Em relação à Figura 5, têm-se a avaliação de atores pertencentes à empresa e ao governo. Verifica-se que a opinião entre estes atores é a mais divergente em relação aos atributos mais relevantes. O aspecto legal, por exemplo, tem uma IR de $27 \%$ para os stakeholders governamentais, sendo considerado o mais relevante; enquanto para os empresariais, a IR é $8 \%$ (ficando à frente apenas do aspecto político em grau de importância). Nota-se, também, haver maior consenso sobre a importância relativa do aspecto técnico e pela menor relevância dos aspectos político e social. 


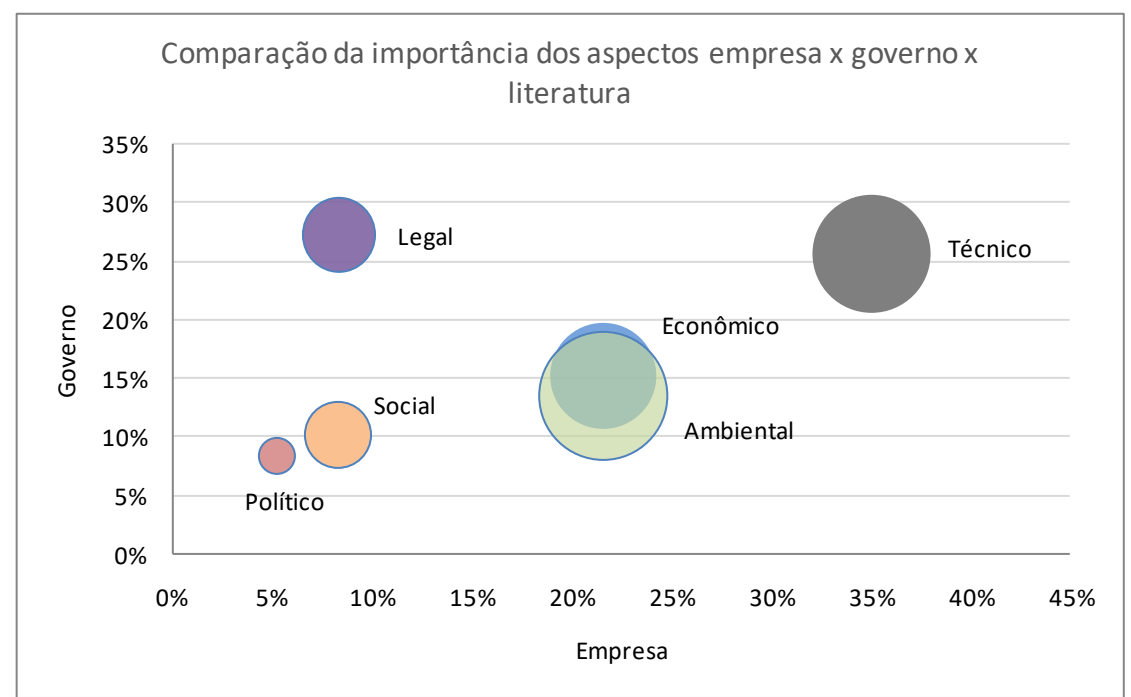

Figura 5. Importância dos aspectos - literatura x empresa x governo

No que diz respeito aos atributos avaliados, têm-se a Figura 6. Verifica-se que, para os acadêmicos, os atributos mais relevantes são "custo x benefício", "método de dragagem" e "sedimentos gerados" (com mediana 9 e IR 22,7\%), além de "legislação nacional" (com mediana 9 e IR 22,5\%). Em seguida, têm-se: "movimentação e impacto da economia local e regional", "características físicas e ambientais", "qualidade da água" e "vida marinha" (mediana 8 e IR 6,3\%). Os atributos considerados menos relevantes foram "aceitação pública" e "relacionamento entre governos" (mediana 6 e IR 2,1\%). Os demais alcançaram mediana 7 e IR 3,5\% (com exceção de "vida fora d'água" que a IR foi 3,6\%). 


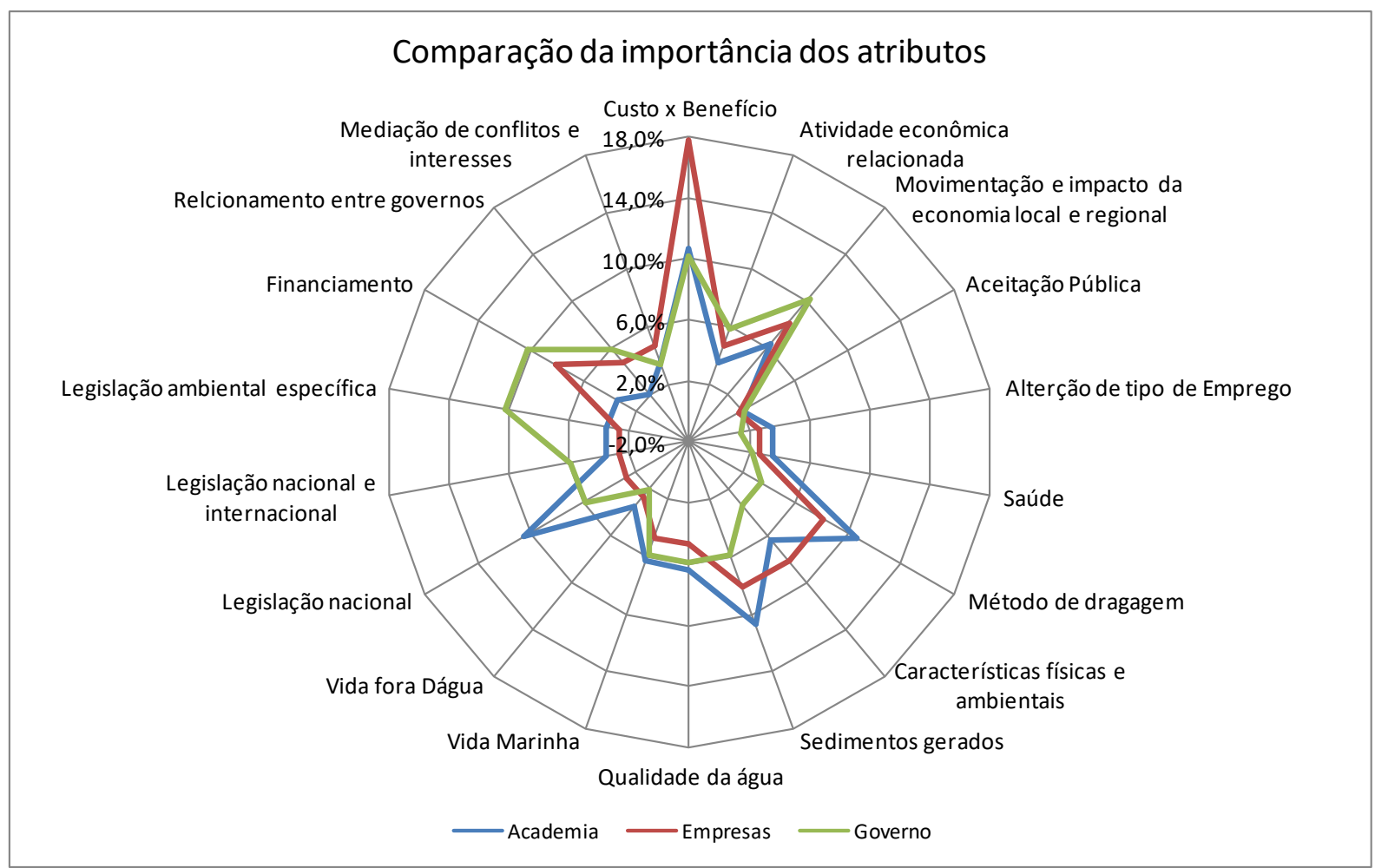

Figura 6. Comparação do grau de importância dos atributos por grupo de stakeholder

Ressalta-se que, dentre os atributos considerados mais relevantes pelos acadêmicos, há um associado a cada aspecto empatado na primeira colocação (com IR 22\%). Os três atributos associados aos aspectos político e social foram considerados pouco relevantes (com IR variando de $2,1 \%$ e $3,5 \%$ ), demonstrando certa consistência na avaliação deste grupo de stakeholders.

Não obstante, apenas o aspecto "técnico" teve todos os atributos considerados relevantes (com IR maior ou igual a 6,3\%), enquanto aspectos social e ambiental tiveram dois atributos considerados relevantes (com IR maior ou igual a 6,3\%). Salienta-se que, em relação ao aspecto legal, embora ele tenha sido considerado tão importante quanto o social, o econômico e o técnico, apenas um atributo foi considerado relevante ("legislação nacional").

Em relação aos stakeholders ligados a empresas, percebe-se maior ênfase ao atributo "custo x benefício", com IR 17,7\%. Destaca-se que estes respondentes foram unânimes ao atribuir nota 9 a este atributo (CV 0\%) que pertence ao aspecto econômico, embora o técnico tenha sido declarado como mais relevante (anteriormente). Em seguida, encontram-se empatados "movimentação e impacto da economia local e regional", "método de dragagem", "características físicas e ambientais", "sedimentos gerados" e "financiamento", com mediana 7 e IR 8,2 , sendo que CV o primeiro atributo teve o maior CV (35\%) e o último teve o menor $(18 \%)$.

Verifica-se, portanto, que os três atributos associados ao aspecto técnico foram considerados relevantes (embora não ocupem a primeira colocação). Ainda, embora o aspecto ambiental tenha sido avaliado como tão importante quanto o econômico por este grupo de stakeholder, nenhum atributo ambiental teve destaque.

Além disso, o atributo "financiamento" foi considerado fundamental para definição dos portos a serem dragados, embora, anteriormente, o aspecto político tenha sido considerado o menos relevante. Isso indica que talvez estes atores não tenham compreensão 
acurada sobre o tema uma vez que o maior financiador das dragagens no Brasil é o governo. Os demais atributos do aspecto político obtiveram um IR igual aos atributos ambientais que avaliam o impacto dentro d'água (mediana 6 e IR 4,7). O atributo considerado menos relevante foi "aceitação pública" com IR 1,7\%, embora seu CV seja alto (88\%). Nenhum dos atributos sociais ou legais foi considerado importante, acompanhando a baixa importância relativa dada a estes aspectos, anteriormente.

$\mathrm{Na}$ opinião dos atores governamentais, destacam-se os atributos "custo x benefício", "movimentação e impacto da economia local e regional", "legislação ambiental específica" e "financiamento", com mediana 8 e IR 10,2\%. Em seguida, estão empatados com o mesmo grau relevância: "atividade econômica relacionada", "sedimentos gerados", "qualidade da água", "vida marinha", "legislação nacional", "legislação internacional" e "relacionamento entre governos", com mediana 7 e IR 5,9\%.

Os demais atributos obtiveram um IR igual ou menor a 3,4\%. Salienta-se que o CV do atributo "atividade econômica relacionada" é igual a zero, o que indica consenso dos especialistas em relação à nota atribuída. No outro extremo, o atributo "vida for a d'água" apresentou CV igual a $100 \%$, o que mostra que os especialistas desse grupo discordam sobre a importância relativa deste item. Apenas este atributo teve CV 100\%, embora muitos atributos tenham tido $\mathrm{CV}$ acima de $50 \%$ na avaliação de atores de diferentes grupos, mostrando diferenças no julgamento de cada um deles.

Ressalta-se que embora os atores governamentais tenham declarado que os aspectos legal e técnico têm maior relevância na priorização da dragagem, apenas um dos três atributos técnicos foi considerado relevante. Por sua vez, todos os atributos econômicos obtiveram destaque, embora este aspecto tenha obtido apenas a terceira colocação (com IR 15\%). Ainda, apesar do atributo político ter alcançado um IR de $8 \%$, dois de seus atributos foram considerados fundamentais. Isso demonstra falta de compreensão quanto ao enquadramento de cada atributo no respectivo aspecto.

É importante mencionar que, embora tenha sido atribuídos graus de importância diferentes, os atributos "custo x benefício", "movimentação e impacto na economia local e regional" (para o aspecto econômico) e "sedimentos gerados" (para o aspecto técnico), foram considerados relevantes pelos três grupos. Entretanto, apenas "custo x benefício" foi apontado como o item mais relevante (com maior IR) pelos três, corroborando, inclusive o estudo de Guimarães et al. (2016). Evidencia-se, ainda, que apenas os stakeholders acadêmicos indicaram o atributo econômico dentre os mais relevantes. Isso se deve ao elevado custo associado ao processo de dragagem.

Ainda, "atividade econômica relacionada", "legislação internacional", "legislação ambiental específica" e "relacionamento entre governos" foram considerados relevantes apenas pelo grupo governamental. A Tabela 3 consolida as avaliações feitas por cada grupo de stakeholder. 
Tabela 3: Síntese das avaliações feitas por cada grupo de stakeholder

\begin{tabular}{|c|c|c|c|c|c|c|c|c|c|c|c|c|c|c|c|c|c|c|}
\hline \multirow{3}{*}{$\begin{array}{l}\frac{8}{0} \\
\frac{0}{2} \\
\frac{0}{2}\end{array}$} & \multicolumn{7}{|c|}{ Avaliação dos aspectos pelos stakeholders } & \multirow{3}{*}{ Atributos } & \multicolumn{3}{|c|}{ Academia } & \multicolumn{3}{|c|}{ Empresa } & \multicolumn{3}{|c|}{ Governo } & \multirow{3}{*}{$\begin{array}{l}\text { Freq. } \\
\text { Literatura }\end{array}$} \\
\hline & \multicolumn{2}{|c|}{ Academia } & \multicolumn{2}{|c|}{ Empresa } & \multicolumn{2}{|c|}{ Governo } & \multirow[t]{2}{*}{ FL } & & \multirow[b]{2}{*}{$A H P$} & \multirow[b]{2}{*}{ Med. } & \multirow[b]{2}{*}{$C V$} & \multirow[b]{2}{*}{$A H P$} & \multirow[b]{2}{*}{ Med. } & \multirow[b]{2}{*}{$C V$} & \multirow[b]{2}{*}{$A H P$} & \multirow[b]{2}{*}{ Med. } & \multirow[b]{2}{*}{$C V$} & \\
\hline & IR & $\mathrm{CV}$ & IR & $\mathrm{CV}$ & IR & $\mathrm{CV}$ & & & & & & & & & & & & \\
\hline \multirow{3}{*}{ 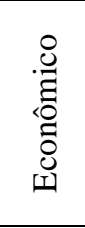 } & \multirow{3}{*}{$22 \%$} & \multirow{3}{*}{$11 \%$} & \multirow{3}{*}{$22 \%$} & \multirow{3}{*}{$22 \%$} & \multirow{3}{*}{$15 \%$} & \multirow{3}{*}{$13 \%$} & \multirow{3}{*}{34} & Custo x Benefício & $10,7 \%$ & 9 & $11 \%$ & $17,7 \%$ & 9 & $0 \%$ & $10,2 \%$ & 8 & $38 \%$ & 11 \\
\hline & & & & & & & & $\begin{array}{ll}\text { Atividade } & \text { econômica } \\
\text { relacionada } & \\
\end{array}$ & $3,5 \%$ & 7 & $14 \%$ & $4,7 \%$ & 6 & $21 \%$ & $5,9 \%$ & 7 & $0 \%$ & 14 \\
\hline & & & & & & & & $\begin{array}{l}\text { Movimentação e impacto da } \\
\text { economia local e regional }\end{array}$ & $6,3 \%$ & 8 & $31 \%$ & $8,2 \%$ & 7 & $35 \%$ & $10,2 \%$ & 8 & $25 \%$ & 9 \\
\hline \multirow{3}{*}{$\begin{array}{l}. \bar{J} \\
0 \\
0 \\
\infty\end{array}$} & & & & & & & & Aceitação Pública & $2,1 \%$ & 6 & $42 \%$ & $1,7 \%$ & 4 & $88 \%$ & $2,1 \%$ & 5 & $20 \%$ & 4 \\
\hline & $8 \%$ & $43 \%$ & $8 \%$ & $33 \%$ & $10 \%$ & $43 \%$ & 13 & Alteração de tipo de Emprego & $3,5 \%$ & 7 & $14 \%$ & $2,7 \%$ & 5 & $39 \%$ & $1,5 \%$ & 4 & $50 \%$ & 4 \\
\hline & & & & & & & & Saúde & $3,5 \%$ & 7 & $64 \%$ & $2,7 \%$ & 5 & $50 \%$ & $2,1 \%$ & 5 & $60 \%$ & 5 \\
\hline & & & & & & & & Método de dragagem & $10,7 \%$ & 9 & $22 \%$ & $8,2 \%$ & 7 & $21 \%$ & $3,4 \%$ & 6 & $67 \%$ & 10 \\
\hline : & $22 \%$ & $6 \%$ & $35 \%$ & $15 \%$ & $26 \%$ & $22 \%$ & 42 & $\begin{array}{l}\text { Características físicas e } \\
\text { ambientais }\end{array}$ & $6,3 \%$ & 8 & $19 \%$ & $8,2 \%$ & 7 & $21 \%$ & $3,4 \%$ & 6 & $67 \%$ & 11 \\
\hline & & & & & & & & Sedimentos gerados & $10,7 \%$ & 9 & $11 \%$ & $8,2 \%$ & 7 & $21 \%$ & $5,9 \%$ & 7 & $29 \%$ & 21 \\
\hline & & & & & & & & Qualidade da água & $6,3 \%$ & 8 & $25 \%$ & $4,7 \%$ & 6 & $33 \%$ & $5,9 \%$ & 7 & $29 \%$ & 18 \\
\hline है & $22 \%$ & $11 \%$ & $22 \%$ & $57 \%$ & $12 \%$ & $25 \%$ & 50 & Vida Marinha & $6,3 \%$ & 8 & $25 \%$ & $4,7 \%$ & 6 & $25 \%$ & $5,9 \%$ & 7 & $43 \%$ & 18 \\
\hline & & & & & & & & Vida fora D'água & $3,6 \%$ & 7 & $29 \%$ & $2,7 \%$ & 5 & $55 \%$ & $2,1 \%$ & 5 & $100 \%$ & 14 \\
\hline & & & & & & & & Legislação nacional & $10,5 \%$ & 9 & $22 \%$ & $2,7 \%$ & 5 & $50 \%$ & $5,9 \%$ & 7 & $43 \%$ & 3 \\
\hline$\overline{6}$ & $22 \%$ & $17 \%$ & $8 \%$ & $50 \%$ & $27 \%$ & $11 \%$ & 16 & Legislação internacional & $3,5 \%$ & 7 & $29 \%$ & $2,7 \%$ & 5 & $50 \%$ & $5,9 \%$ & 7 & $29 \%$ & 8 \\
\hline 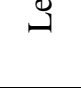 & & & & & & & & $\begin{array}{ll}\text { Legislação } & \text { ambiental } \\
\text { específica }\end{array}$ & $3,5 \%$ & 7 & $43 \%$ & $2,7 \%$ & 5 & $40 \%$ & $10,2 \%$ & 8 & $38 \%$ & 5 \\
\hline & & & & & & & & Financiamento & $3,5 \%$ & 7 & $29 \%$ & $8,2 \%$ & 7 & $18 \%$ & $10,2 \%$ & 8 & $38 \%$ & 2 \\
\hline 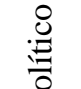 & $5 \%$ & $25 \%$ & $5 \%$ & $50 \%$ & $8 \%$ & $29 \%$ & 4 & $\begin{array}{l}\text { Relacionamento entre } \\
\text { governos }\end{array}$ & $2,1 \%$ & 6 & $50 \%$ & $4,7 \%$ & 6 & $59 \%$ & $5,9 \%$ & 7 & $57 \%$ & 1 \\
\hline 2 & & & & & & & & $\begin{array}{llll}\text { Mediação } & \text { de } & \text { conflitos } & \mathrm{e} \\
\text { interesses }\end{array}$ & $3,5 \%$ & 7 & $36 \%$ & $4,7 \%$ & 6 & $50 \%$ & $3,4 \%$ & 6 & $50 \%$ & 1 \\
\hline
\end{tabular}


Ao analisar a importância de cada atributo por aspecto e por stakeholder (Figura 7), verifica-se que "custo x benefício" é considerado o atributo mais relevante para o aspecto econômico enquanto "atividade econômica relacionada" é considerado o menos importante, para os três grupos de stakeholders. Além disso, nota-se que "custo benefício" é enfatizado pelos atores de empresas, enquanto "atividade econômica relacionada" e "movimentação e impacto da economia local e regional" obtiveram maior nota com atores governamentais. Enfatiza-se que "custo benefício" foi o atributo com maior nota entre todos os avaliados (IR $17,7 \%$ pelos atores empresariais, com CV 0\%, demonstrando consenso absoluto sobre sua importância para este grupo).

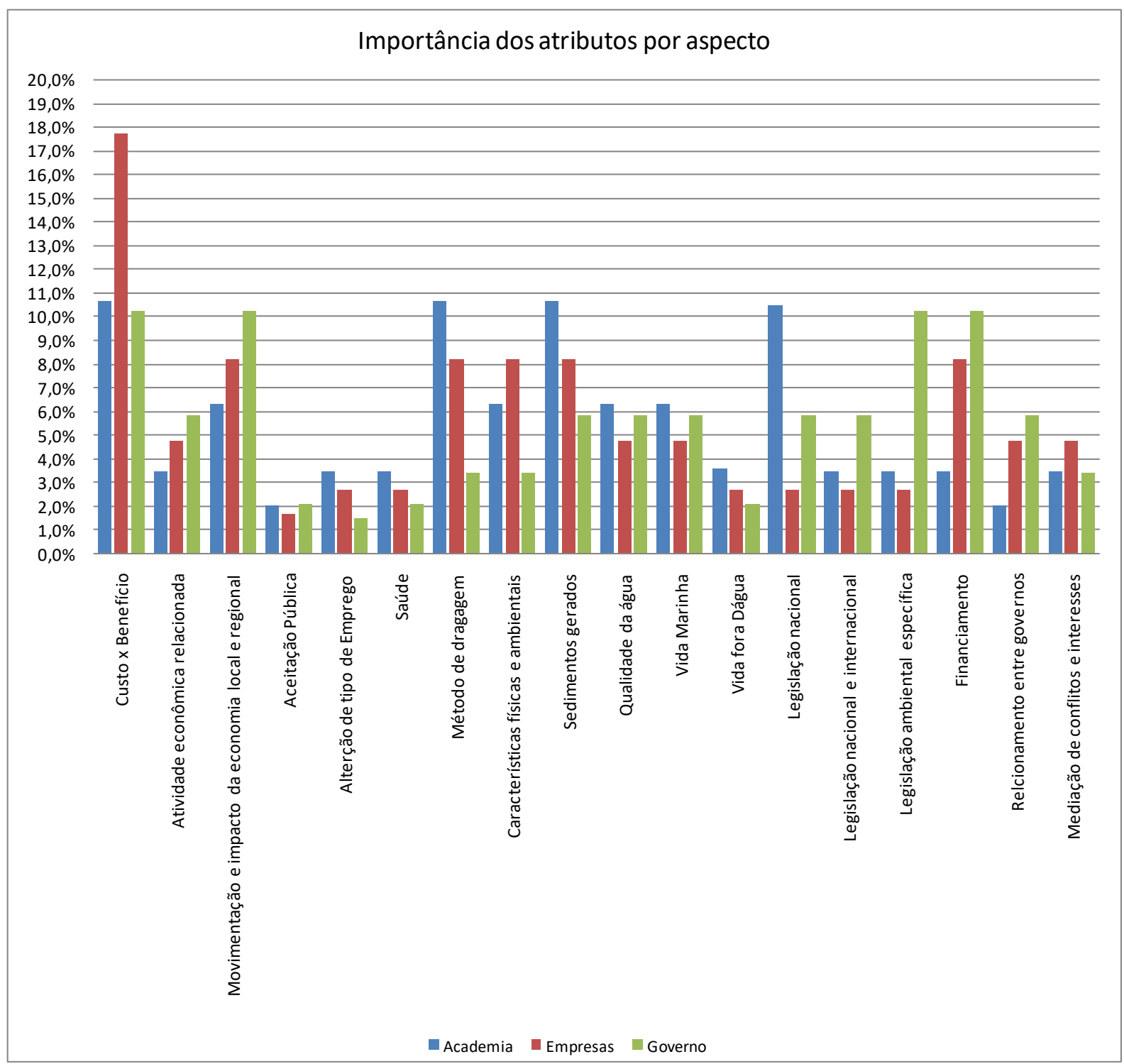

Figura 7. Comparação do grau de importância dos atributos por aspecto e por grupo de stakeholder.

Em relação ao aspecto social, verifica-se que os três atributos apresentam as menores importâncias relativas entre todos àqueles analisados. "Saúde" e "alteração no tipo de 
emprego" têm uma importância levemente maior que "aceitação pública" para os atores acadêmicos e empresariais. Enfatiza-se que "alteração no tipo de emprego" foi o atributo que obteve menor nota entre todos analisados (IR 1,5\% pelos atores governamentais, com CV $50 \%$, demonstrando que não houve consenso), seguido por "aceitação pública" (IR 1,7\% pelos atores empresariais, com CV 88\%).

Quanto aos atributos técnicos, "métodos de dragagem" e "sedimentos gerados" apresentaram maior relevância, sendo mais enfatizados pelos stakeholders acadêmicos. Para os empresariais, os três atributos têm importância igual (IR 8,2\%), enquanto para os governamentais a maior relevância é atribuída aos "sedimentos gerados".

Em relação ao aspecto ambiental, embora seja aquele mais frequente na literatura, verifica-se, na Figura 7, que seus atributos não se destacam com os maiores IR (embora sejam considerados relevantes pelos acadêmicos e governamentais). Percebe-se maior preocupação com os impactos no meio aquático, pela ênfase aos indicadores "qualidade da água" e "impacto na vida marinha", talvez pelas características da própria dragagem (os reflexos fora d'água demoram mais tempo a serem observados).

Sobre os atributos legais, percebe-se grande ênfase dos acadêmicos no que diz respeito à legislação nacional, enquanto os governamentais destacam a legislação ambiental (embora considere todos os atributos deste aspecto relevantes). Os atores provenientes de empresas revelaram não considerá-los relevantes, tendo atribuído a mesma nota aos três atributos (IR $2,7 \%)$.

Por fim, embora o aspecto político tenha sido apontado por todos os grupos como aquele menos relevante dentre os analisados, verifica-se que o atributo "financiamento" se destacou, especialmente, entre atores de empresas e do governo. Isso pode ser explicado pelo fato do financiamento ser fundamental para consecução da dragagem, entretanto, estes grupos podem tê-lo associado ao aspecto econômico (embora a definição da forma de financiamento seja uma decisão política, que cabe ao governo, considerando as características específicas da obra).

"Relacionamento entre governos" e "mediação de conflitos e interesses" foram considerado igualmente importante pelos stakeholders empresariais, enquanto "financiamento" e "mediação de conflitos e interesses" têm o mesmo IR na opinião dos acadêmicos. Já para os atores governamentais, "financiamento" deve ter maior ênfase, seguido pelo e "relacionamento entre governos", por fim, "mediação de conflitos e interesses".

Salienta-se que, embora os grupos tenham declarado que o aspecto social é mais importante que o político, na prática, os atributos políticos receberam maior peso que os sociais. De maneira análoga, embora o atributo ambiental tenha sido considerado relevante, especialmente pelos atores acadêmicos e de empresas, seus atributos tiveram avaliações inferiores aos técnicos, econômicos e legais, em alguns casos (como pode ser visualizado na Figura 7). Cabe refletir se a indicação dos aspectos mais relevantes foi feita de maneira consciente ou apenas seguindo um discurso pronto de "preservação ambiental" e preocupação com o "social". Ressalta-se que esta confusão conceitual sobre os atributos a serem enquadrados em cada aspecto é vista também na literatura.

\section{Considerações Finais}

Com a realização deste estudo foi possível responder as questões relacionadas ao problema de pesquisa. Os aspectos e atributos mais relevantes para priorizar a dragagem em 
portos foram identificados e as respectivas importâncias foram estabelecidas com base na pesquisa com os stakeholders.

Foi possível concluir que há diferença na priorização dos aspectos e atributos dependendo do grupo que esteja tomando a decisão. Isso está associado ao viés inerente a cada stakeholder. O governo prioriza os aspectos econômico, legal e político, enquanto as empresas entendem que os atributos relacionados aos aspectos econômico, político e técnico são mais importantes. Já os acadêmicos priorizam, além dos já citados, o ambiental. Entretanto, nenhum dos grupos pesquisados atribuiu pesos maiores aos atributos relacionados ao aspecto social.

Com base na opinião dos especialistas, observou-se que o aspecto econômico obteve o maior consenso na ordem de importância nos três grupos pesquisados, devido à baixa dispersão das respostas. Já o aspecto social foi aquele com maior dispersão nas respostas de todos os stakeholders que participaram da pesquisa. Ainda, há uma aparente confusão no entendimento relacionado aos atributos econômicos e ambientais com os técnicos e legais, respectivamente.

A diversidade de aspectos e a quantidade de atributos relacionados com a priorização de dragagem em portos marítimos pode tornar o processo de decisão mais complexo. Isso pode levar os empresários a concentrarem as decisões em atributos técnicos e econômicos, enquanto o governo fará exigências legais que podem impactar em questões não tão relevantes do ponto de vista das empresas, como o meio ambiente.

Conclui-se também que a revisão de literatura e a aplicação da AHP permitiram o atingimento dos objetivos definidos para a pesquisa. Os atributos foram levantados e a relevância de cada um foi definida com base na técnica multicritério à decisão escolhida.

A baixa quantidade de literatura relacionada aos aspectos sociais e políticos pode ser considerada uma limitação deste artigo. Entretanto, isto pode estar relacionado ao fato de que o grupo de acadêmicos, que são os que publicam a respeito do tema, atribuem peso menor a estes aspectos, conforme resultados da pesquisa apresentada.

A baixa quantidade de especialistas de cada grupo que responderam ao questionário e a impossibilidade de aplicar um método que permitisse o consenso das respostas, são também consideradas limitações.

Para novos estudos sugere-se a ampliação do número de respondes com a aplicação do método Delphi para melhorar o consenso nas respostas dos especialistas, representado neste trabalho pelo coeficiente de variação das respostas. Outra possibilidade de estudo é o aprofundamento no entendimento dos aspectos considerados menos importantes na visão dos especialistas. Por fim, sugere-se identificação de possibilidades de medição (ou quantificação) dos atributos bem como a sua utilização para elaboração de um ranking de prioridade na dragagem dos portos brasileiros.

Ainda, o desenvolvimento sustentável implica em interdependência das dimensões ambientais, econômicas e sociais, logo, o processo de tomada de decisão pelos stakeholders, mesmo que divergentes em valores, podem auxiliar no planejamento e a gestão dos portos brasileiros. Assim, a aplicação considerando esse enfoque, implicará na priorização das demandas cada vez mais crescente para de dragagem de canais e seus impactos associados.

\section{AGRADECIMENTOS}

Ao CNPq (Processo 308729/2014-5 Bolsa Produtividade em Pesquisa) e FAPERJ (Processo 203986) pelo suporte financeiro. 


\section{REFERÊNCIAS}

Agunwamba J. C., Onuoha K. C., \& Okoye A. C.(2012): Potential effects on the marine environment of dredging of the Bonny channel in the Niger Delta- Niger

Alfredini, P.; \& Arasaki, E. (2014): Obras e Gestão de Portos e Costas: A Técnica Aliada ao Enfoque Logístico e Ambiental- Brazil

Alvarez-Guerra, M., Viguri J. R., Casado-Martínez M. C., \& Delvalls T. A. (2007):

Sediment Quality Assessment and Dredged Material Management in Spain: Part II, Analysis of Action Levels for Dredged Material Management and Application to the Bay of Cádiz. Spain

Angonesi L. G., Bemvenuti C. E., \& Gandra M. S. (2006): Effects of Dredged Sediment Disposal on the Coastal Marine Macrobenthic Assemblage in Southern Brazil. - Brazil

ANTAQ (Org.) (2015): Statistical Yearbook Waterway- Brazil

ANTAQ (Org.) (2011): Statistical Yearbook Waterway- Brazil

ANTAQ (Org.) (2009): Grants for Technical Areas Destined Identification of Organized Ports Installation or Private Use Terminals authorization in Support of the General Concession Plan: Base Review and Adjustments Georeferenced- Brazil

Bebianno, M. J., Pereira, C. G., Rey, F., Cravo, A., Duarte, D., D'errico, G., \& Regoli, F. (2015): Integrated approach to assess ecosystem health in harbor areas- Science of the Total Environment - Portugal

Castro, S. M., \& Almeida, J. R. (2012): Dredging and environmental conflicts in classicand modern harbors: a revision -Magazine Society and Nature - Brazil

Collier, Z. A., Bates, Z. A., Wood, M. D., \& Linkov, I. (2014): Stakeholder engagement in dredged material management decisions - United States

Fadda, E. A. (2012): Legal Instruments Applied to dredging in Brazil-Magazine Customs Law - Brazil

Fettweis, M., Lancker, V. V., Baeye, M., Martens, C., Francken, F., Michielsen, T., Lauwaert, B., \& Eynde, D. V. (2011): Monitoring the effects of disposal of fine sediments from maintenance dredging on suspended particulate matter concentration in the Belgian nearshore area (southern North Sea) - Marine Pollution Bulletin - Belgium

Fórum De Direito Marítimo, Portuário E Logística Do Estado Do Ceará (2012) - A Diagnóstico dos Portos Marítimos. III Fórum de Direito Marítimo, Portuário e Logística do Estado do Ceará. Agosto de 2012 - Ceará

Gomes, L. F. A. M. (2004): Decision making in complex scenes : introduction to discrete methods of multi-criteria decision support - Brazil 
Gomes, L. F. A. M.; \& LIMA, M. M. P. P. (1992). From Modelling Individual Preferences to Multicriteria Ranking of Discrete Alternatives: A Look at Prospect Theory and the Additive Difference Model

Guimarães, V. A.; Accetta, D.; Leal Junior, I. C; Silva, S. D.; Moura, F. G. A.; Siqueira, G. A.; \& Montenegro, T. R. (2016): Selection of criteria for dredging prioritizing in seaports. PIANC-COPEDEC IX, 2016, Rio de Janeiro, Brasil

Kapsimalis, V., Panagiotopoulos, I., Kanellopoulos, T., Hatzianestis, I., Antoniou P., \& Anagnostou, C. (2010): A multi-criteria approach for the dumping of dredged material in the Thermaikos Gulf, Northern Greece- Journal of Environmental Management- Greece

Kiker, G. A., Bridges, T. S., Varghese, A., Seager, T. P., \& Linkov, I. (2005): Application of Multicriteria Decision Analysis in Environmental Decision Making - Integrated Environmental Assessment and Management - United States

Leal Jr, I. C. (2010). Método de Escolha Modal para transporte de produtos perigosos com base em medidas de ecoeficiência. Tese de doutorado. Rio de Janeiro: UFRJ/COPPE, 2010

Lobedan, F. R., LaBasco, T., \& Ogunfunmi, K. (2012):Wharf embankment and strengthening program at the Port of Oakland-Soil Dynamics and Earthquake Engineering - United States

Lukens, J. L. (2000):National Coastal Program Dredging Policies: An Analysis of State, Territory, \& Commonwealth Policies Related to Dredging \& Dredged Material Management OCRM/CPD Coastal Management Program Policy Series, Technical Document 00-02 United States

Manap, N., Voulvoulis, N. (2014): Risk-based decision-making framework for the selection of sediment dredging option. 2014. Science of the Total Environment - United Kingdom

Marine Sacs Project (Org.). (2006): Environmental impacts of dredging on seagrasses: A review.- United States

Ministry Of Transport (Org.) (2007): National Plan of Logistics and Transport : Executive Summary - Brazil

Ministry Of Transport (Org.) (2009): Executive Report PNLT - Brazil

Ports Australia (Org.)(2014): Dredging and Australian Ports: Subtropical and Tropical PortsAustralia

Saaty, T. L. (1980): The Analytic Hierarchy Process: Planning, Priority Setting, Resource Allocation- United States

Scheffler, A., Roth, T., \& Ahlf W. (2014): Sustainable decision making under uncertainty: a case study in dredged material management - Environmental Sciences Europe. 
SEP - SECRETARIAT OF PORTS (Org) (2014): Brazilian Port Sector and the National Dredging Program II - Brazil

SEP - SECRETARIAT OF PORTS (Org.)(2012): National Plan for Port Logistics : Master Plans - Brazil

Sheehana, C., Harrington, J. (2012): An environmental and economic analysis for geotube coastal structures retaining dredge material- Resources, Conservation and Recycling - Ireland

Smith, T. W. P.; Jalkanen, J. P.; Anderson, B. A.; Corbett, J. J.; Faber, J.; Hanayamas, S.; O'keeffe, E., Parker, S., Johansson, L., Aldous, L., Raucci, C., Traut, M.; Ettinger, S.; Nelissen, D.; Lee, D. S.; NG, S.; Agrawal, A.; Winebrake, J. J.; Hoen, M., Chesworth, S. E.; \& Pandey, A. (2015) Third IMO GHG Study 2014. International Maritime Organization (IMO), Londres, Inglaterra.

Stopford, M. (2008): Maritime Economics. Taylos and Francis. $3^{\text {rd }}$ edition.

UNCTAD (2016) Review of Maritime Transport 2015. United Nations publication. Sales no. E.16.II.D.7. New York and Geneva

Vikolainen, V., Bressers H., \& Lulofs K. (2014): A Shift Toward Building with Nature in the Dredging and Port Development Industries: Managerial Implications for Projects in or Near Natura 2000 Areas - Environmental management - Netherlands 